\title{
Can State Courts Cure Partisan Gerrymandering: Lessons from League of Women Voters v. Commonwealth of Pennsylvania (2018)
}

\author{
Bernard Grofman and Jonathan R. Cervas
}

\begin{abstract}
In League of Women Voters et al. v. Commonwealth of Pennsylvania et al. (2018), henceforth abbreviated $L W V$, the Pennsylvania Supreme Court struck down that state's congressional plan as an unconstitutional partisan gerrymander. It did so entirely on state law grounds after a three-judge federal court had rejected issuing a preliminary injunction against the plan. The aim of this essay is to examine the implications of $L W V$ for future partisan gerrymandering litigation. In particular, we look toward the applicability of the Pennsylvania court's approach to other potential partisan gerrymandering challenges brought under state law, especially those in the 12 states whose state constitutions have provisions essentially identical to the one relied upon by the Pennsylvania Supreme Court, and in states with similar provisions. We pay particular attention to how the court made use of the expert witness testimony in the case, relying on some of it, while rejecting or critiquing the applicability of other elements, since such a discussion can inform future litigation in state courts drawing on the $L W V$ opinion for ideas. In our concluding discussion we contrast the criteria used to evaluate partisan gerrymandering by this court with those used by federal courts, and we look at how it may impact the decisions of legislators about line drawing in 2020.
\end{abstract}

Keywords: partisan gerrymandering, redistricting, public law, constitutions, state legislatures

\section{INTRODUCTION}

$\mathbf{L}$ EGENDARY SONG WRITER WOODY GUTHRIE'S ballad about "Pretty Boy Floyd" contains the immortal line: "Some will rob you with a six-gun, and some with a fountain pen." If Guthrie were writing today, he might have written "Some will rob you with a six-gun, and some with computer-aided sophisticated partisan gerrymandering." Until this year, the consensus among redistricting experts was that, unless
Bernard Grofman is the Jack W. Peltason (Bren Foundation Endowed) Chair of Democracy Studies and Professor of Political Science at the University of California, Irvine. He has drawn remedial redistricting plans for federal courts and has testified as an expert in numerous redistricting cases. He is the co-author of an Amicus Brief in League of Women Voters v. Commonwealth of Pennsylvania (2018) on behalf of neither party. Grofman's work on this project was supported by the Jack W. Peltason (Bren Foundation) Chair at the University of California, Irvine. Jonathan Cervas is a $\mathrm{PhD}$ candidate in political science at the University of California, Irvine, with an interest in elections and skills in geographic information systems. Together with Grofman, Cervas prepared the reme- dial maps in service to the U.S. District Court of Utah for the County Commission and School Board for San Juan County (Navajo Nation et al. v. San Juan County et al. [12/ 21/2017]). Cervas's work on this project was supported by both the Peltason Chair and the University of California, Irvine School of Social Sciences. The authors would like to especially thank Jonathan Lai of the Philadelphia Inquirer for his helpful suggestions. Additionally, Esther E. Bailey, Christopher S. Elmendorf, Pooya Safarzadeh, Charles Anthony Smith, Aruhn Venkat, Election Law Journal editor David Canon, and three anonymous reviewers provided the authors with valuable comments and discussions for which we are very grateful. 
we got a 5-4 decision from the Supreme Court that ratified lower court findings about unconstitutional partisan gerrymandering in Wisconsin and North Carolina, partisan gerrymandering would not have a court remedy in our lifetime; although in a few states, initiatives might take redistricting out of the hands of legislators in ways that might reduce the likelihood of partisan gerrymandering. ${ }^{1}$

The other obvious route, attacking partisan gerrymandering under provisions of a state constitution rather than federal law, was expected to be a waste of time, except in Florida. A "Fair Districts Amendment" that imposed a variety of "good government" requirements on Florida redistricting, including forbidding the Florida Legislature from drawing a redistricting plan or an individual district with the "intent to favor or disfavor a political party or an incumbent," was added to the Florida Constitution in 2010 by the voters. Provisions of the amendment were used by the Florida Supreme Court in 2012 to strike down the entire state senate plan, and then relied upon in 2015 to strike down some congressional districts in that state as unconstitutional partisan gerrymanders. But the very specific language of that initiative regarding the eschewing of political considerations does not exist in other state constitutions.

In early 2018 everything changed. In League of Women Voters v. Pennsylvania, decided January 22, 2018 (henceforth abbreviated $L W V$ ), ${ }^{2}$ the Pennsylvania Supreme Court offered a new and distinctive test for unconstitutional partisan gerrymandering under which it found the state's congressional districts to violate a very longstanding provision of the state's constitution. The Pennsylvania Supreme Court held that "the fact that the 2011 Plan cannot, as a statistical matter, be a plan directed at complying with traditional redistricting requirements is sufficient to establish that it violates the Free and Equal Elections Clause [of the Pennsylvania State Constitution]" 3 (slip op. at p.128, emphasis added). In contrast, in 2017 , in a separate challenge to Pennsylvania's congressional districts, this one brought in federal court under the Elections Clause of the U.S. Constitution, in a $2-1$ vote, a three-judge court rejected the viability of bringing a challenge on this legal basis. ${ }^{4}$

But, just as $L W V v$. Pennsylvania signaled a potential sea change in how state courts could address partisan gerrymandering, 2018 also saw what most observers would label a dramatic shift in federal partisan gerrymandering jurisprudence. Gill $v$. Whitford, a challenge to Wisconsin's legislative plan as an unconstitutional partisan gerrymander that had been successful at the district court level, was heard by the U.S. Supreme Court, and in a 7-2 opinion authored in June 2018 by Justice Roberts, that challenge was remanded back to the lower court. In that remand decision, the Supreme Court has now made clear that evidence of unconstitutional gerrymandering - in the form of packing or cracking (see definitions later below)-must be demonstrated in individual districts and that only voters in those districts have standing to sue. A week later, the U.S. Supreme Court similarly remanded a successful North Carolina congressional partisan gerrymandering challenge back to the lower court. Additionally, they returned a partisan gerrymandering challenge to Maryland's 6th

${ }^{1}$ For example, while California's redistricting initiative imposed multiple redistricting criteria, it ultimately relies on taking the redistricting process out of the hands of the legislature and placing it into the hands of a tripartite commission with very complex membership requirements and super-majoritarian agreement for its redistricting decisions (see, e.g., discussion in Miller and Grofman (2013)). In Ohio, a different approach was taken to curb partisan gerrymandering, but also by initiative. The initiative passed in Ohio in 2018 requires bipartisan agreement for the passage of redistricting legislation (Wilson 2018). ${ }^{2}$ Formally, the case is known as League of Women Voters of Pennsylvania, Carmen Febo San Miguel, James Solomon, John Greigner, John Capowski, Gretchen Brandt, Thomas Rentschler, Mary Elizabeth Lawn, Lisa Isaacs, Don Lancaster, Jordi Comas, Robert Smith, William Marx, Richard Mantell, Priscilla Mcnulty, Thomas Ulrich, Robert Mckinstry, Mark Lichty, Lorrain Petrosky, Petitioners v. The Commonwealth of Pennsylvania; The Pennsylvania General Assembly; Thomas W. Wolf, in his capacity as Governor of Pennsylvania, Micahel J. Stack III, in his capactiy as Lieutenant Governor of Pennsylvania and President of the Pennsylvania Senate; Michael C. Turzai, in his capacity as Speaker of the Pennsylvania House of Representatives; Joesph B. Scarnati III, in his capacity as Pennsylvania Senate Pro Tempore; Robert Torres, in his capacity as Acting Secretary of the Commonwealth of Pennsylvania; Jonathan M. Marks, in his capacity as Commissioner of the Bureau of Commissions, Elections, and Legislation of the Pennsylvania Department of State, Respondents, (Pennsylvania Supreme Court Middle District, No. 159 MM 2017), and League of Women Voters, et al. v. the Commonwealth of Pennsylvania, et al., 159 MM 2017. We will refer to it through this article as $L W V$ and as League of Women Voters $v$. Pennsylvania.

3 "Elections shall be free and equal; and no power, civil or military, shall at any time interfere to prevent the free exercise of the right of suffrage." Pa. Const. art. I, $\S 5$.

${ }^{4}$ The appeal of that case has arguably been mooted by the state court opinion. 
Congressional District back to the lower court on the grounds that it was not yet ripe for Supreme Court review. ${ }^{5}$ As of this writing (August 2018), only one of these cases has yet resulted in a new lower court ruling, and that case, from North Carolina, has yet to result in a definitive ruling from the trial court as to the next steps necessary to remedy the violation found. And, of course, that ruling in turn would almost certainly result in further Supreme Court review. So we are still in a situation in which the U.S. Supreme Court has yet to utter anything like the final word regarding federal standards for unconstitutional gerrymandering.

A partisan gerrymandering case from Michigan (League of Women Voters of Michigan v. Johnson) is also presently being litigated in a federal court, with trial tentatively set for $2019 .{ }^{6}$ In sum, while the status of partisan gerrymandering challenges at the federal level remains almost as opaque as it has for the 30-plus years since Bandemer v. Davis, one key point that has now been clarified is that, if there is to be a federal standard for when partisan gerrymandering becomes unconstitutional, it will be one relying on district-specific evidence. ${ }^{7}$

However, even if the Supreme Court eventually enunciates a federal standard for unconstitutional partisan gerrymandering that allows some districts in Wisconsin, North Carolina, Maryland, and/or in Michigan to be struck down - and there is no certainty that this will happen $-L W V$ remains a very important case. Not only is the standard used to strike down the Pennsylvania congressional plan in $L W V$ quite distinct from (and arguably easier to satisfy than) any standard likely to be adopted by the U.S. Supreme Court, relying as it does primarily on statewide evidence, but the relevance of this state court decision is not limited to Pennsylvania. Language virtually identical to the provision of the Pennsylvania constitution on which the Pennsylvania Supreme Court relied on is found in the constitutions of another dozen states, and rather similar language is found in other state constitutions (see Elmendorf 2018 and further discussion later in this article). Thus, the Pennsylvania case may have consequences nationwide if state courts take up the Pennsylvania Supreme Court's invitation to deal with partisan gerrymandering challenges as a matter of state rather than federal law. Moreover, the Pennsylvania Supreme Court's consideration of district-specific evidence might even be relevant in informing the ultimate U.S. Supreme
Court decision about federal standards. But in any case, even if the U.S. Supreme Court does eventually enunciate a district-based standard, state courts might still provide the major barrier to future partisan gerrymandering, since the adopted federal standard may be such that very few individual districts end up being struck down.

${ }^{5}$ The Maryland challenge was to only one congressional district, CD6.

${ }^{6}$ While the Plaintiff's December 22, 2017 complaint in this case does detail irregularities in specific districts, it is mostly directed to illustrating what it asserts to be state-wide partisan inequities. However, in light of the Gill v. Whitford remand, we would expect an amended complaint to be filed in Michigan that would be more district-focused.

${ }^{7}$ The standards for partisan gerrymandering previously proposed by just about all social scientists (e.g., partisan asymmetry, the mean-median gap, and the efficiency gap) rely on jurisdiction-wide analyses. Thus, the new federal requirement for a district-specific approach to partisan gerrymandering was a gut-punch for social scientists who define unconstitutional partisan gerrymandering in terms of statewide partisan disparities. This new standard requires us to go back to the drawing boards in a search for manageable standards to distinguish unconstitutional line drawing from politics as usual. However, how to craft district-specific federal standards for partisan gerrymandering must be left as a topic for a different essay. For some preliminary thoughts on this question, see a Monkey Cage essay by Bernard Grofman in the (online) Washington Post (Grofman 2018b). He notes that racial gerrymandering in the form of packing or cracking, or the question of whether race was a preponderant motive in line-drawing (see, e.g., Thornburg v. Gingles, 478 U.S. 30 (1986), Shaw v. Hunt, 517 U.S. 899 (1996), Page v. Va. State Bd. of Elections (Page II), Civil Action No. 3:13cv678 (E.D. Va. June 5, 2015)), is most often addressed in a district-specific way that can be used to inform similar district-specific analyses of partisan gerrymandering. He calls favorable attention to the methods of analysis to study partisan gerrymandering at the district-level used by Professor Kennedy in his testimony in $L W V v$. Pennsylvania. Also, as noted previously, the Florida Constitution has a provision inserted by initiative, Art. III, $\S 20$ (a), that mandates that "[n]o apportionment plan or individual district shall be drawn with the intent to favor or disfavor a political party or an incumbent" (emphasis added), so an examination of the Florida Supreme Court's ruling in League of Women Voters $v$. Detzner, 172 So. 3d 363, 427 (Fla. 2015), may be instructive. Moreover, we believe that some jurisdiction-wide methods, especially those involving comparisons to computer simulations of plans drawn according to "good government" criteria, can be adapted to the presentation of district specific evidence of gerrymandering by looking toward statistical determination of "outlier" status for particular districts in a challenged planthough the statistical power of such tests may be constrained in the case of congressional elections by the limited number of districts in a state's congressional delegation. This argument is fully developed in an essay by one of the present authors (Grofman 2018a). 


\section{A brief history of the Pennsylvania litigation}

As noted above, in League of Women Voters $v$. Pennsylvania, the Pennsylvania Supreme Court found that the congressional plan in Pennsylvania was an unconstitutional partisan gerrymander under Pennsylvania state law. The plan that was struck down was passed in 2011 (25 P.S. § 3596.101 et seq.) when both branches of the legislature and the governorship were in Republican hands. Prior to the lawsuit, the 2011 plan was widely regarded by experts as among the most egregious partisan gerrymanders of the 2010 round of redistricting (see, e.g., Royden and Li 2017), with some even identifying it as the most egregious (Wang 2016a, esp. Fig. 3). ${ }^{8}$ Before the Pennsylvania Supreme Court exercised its powers of extraordinary relief, it ordered the Commonwealth Court to assign a judge to hold a trial and then issue findings of fact and conclusions of law. In his review, the trial judge found, in essence, that the legislative process through which the plan had been chosen demonstrated the indicia of a partisan gerrymander, that the weird shapes of a number of the districts demonstrated the indicia of a partisan gerrymander, that the dismemberment of municipalities, townships, and counties in the state demonstrated the indicia of a partisan gerrymander, that the cracking and packing of Democrat-leaning voters demonstrated the indicia of a partisan gerrymander, and that the frozen $13 \mathrm{R}-5 \mathrm{D}$ results over the course of three elections in a state that is highly politically competitive statewide demonstrated the indicia of a durable partisan gerrymander.

The trial judge also found that none of these features of the map could be explained as necessitated by the electoral geography and demography of the state, though he suggested the possibility that consideration such as incumbency protection might have mattered. Having reached these findings of fact, the trial court then went on to say that, as a matter of law, there was nothing it could do about the problem under the Pennsylvania Constitution: "Petitioners have not articulated a judicially manageable standard by which this Court can discern whether the 2011 Plan crosses the line between permissible partisan considerations and unconstitutional partisan gerrymandering under the Pennsylvania Constitution" (slip op. No. 261 M.D. 2017, p. 126). The trial court magistrate did, however, express the hope that the Supreme Court might, in pending cases, identify manageable standards to provide future guidance to other courts.
But, mirabile dictu, somewhat like a magician pulling a rabbit from a hat, in reviewing the magistrate's ruling, on January 22, 2018, the Pennsylvania Supreme Court found in the "Free and Equal Elections" clause in the Pennsylvania Constitution a bar against partisan gerrymandering, ${ }^{9}$ and one which could be used to craft a manageable standard for unconstitutional gerrymandering. In dramatic contrast to the lower court's conclusion of law, the Pennsylvania Supreme Court held, as quoted earlier, that "the fact that the 2011 Plan cannot, as a statistical matter, be a plan directed at complying with traditional redistricting requirements is sufficient to establish that it violates the Free and Equal Elections Clause [of the Pennsylvania State Constitution]" (slip op., p.128, emphasis added). ${ }^{10}$ In support of its readings of this clause, the court majority provided a long and very carefully crafted historical and legal narrative about the democratic spirit in Pennsylvania. ${ }^{11}$ On February 5, 2018, Justice Alito of the U.S. Supreme Court denied a request by the legislative

${ }^{8}$ See also McGann et al. (2015, 2016).

${ }^{9}$ Supreme Court of Pennsylvania Middle District.

10 "Elections shall be free and equal; and no power, civil or military, shall at any time interfere to prevent the free exercise of the right of suffrage." Pa. Const. art. I, $\S 5$.

${ }^{11}$ In any legal judgment where there are one or more continua along which alternatives can be arrayed, courts must confront the classic problem of sorites, i.e., how to partition things into categories, such as constitutional and unconstitutional. As is argued in Grofman and Gaddie (2017), expanding upon a helpful suggestion by Rachel Apter, courts almost never have to make this choice in voting rights cases of first impression, since such cases involve what Grofman (in earlier unpublished work) referred to as "horribles." Horribles have case facts so extreme that it is easy to decide that they are unconstitutional without ever having to be precise about where the line ultimately is to get drawn. We regard the Pennsylvania congressional districting plan that was overturned as such a "horrible." What we have seen in other voting rights areas such as "one person, one vote" is that it may take multiple decades before courts settle on a "bright-line" test, often converging on such a test from both sides. Of course, such a bright line test is often inherently arbitrary, but, when the standard is a reasonable one, that arbitrariness is outweighed by the usefulness of having those litigating cases and those who seek to avoid their decisions being challenged able to know in advance (or at least have great confidence about) how courts will decide cases because the meaning of precedent can be more precisely specified (see also Grofman (1992)). However, we would also acknowledge that there could be considerable difficulty in converting the standards enunciated by the Pennsylvania Supreme Court into a bright-line test since, if the test were to be limited to only the consideration of violations of good government standards, that will generate a virtual certainty that stealth partisan gerrymanders will fly under state court radar screens. 
leadership of Pennsylvania for a stay of the state court order. ${ }^{12}$ The Pennsylvania Supreme Court subsequently gave the Commonwealth of Pennsylvania until February 15, 2018, to submit to a plan that passed muster both with a Republican-controlled legislature and the current governor, Democrat Tom Wolf, elected in 2014. As expected, the Democrats and Republicans were unable to reach agreement on a plan.

Had such a plan been submitted, the court would have reviewed its constitutionality. In the absence of a state plan, the court invited submissions of plans from the parties to the lawsuit, as well as the intervenors. The court order in February 2018 inviting submissions of feasible maps mentioned only good government criteria: minimizing the number of county, township, and municipality splits, and maximizing district compactness under several different measures of compactness. The Republican legislative leaders jointly (henceforth Joint Plan), the Democratic governor, Democrats within each branch of the legislature, and the Democratic lieutenant governor submitted plans.

The court rejected all of the proposed plans, instead adopting a plan of its own drawn by the court's consultant, Professor Nathan Persily (Stanford Law School). ${ }^{13}$ In its order adopting that plan, the court provided no critique of any of the newly proposed plans in partisan terms, but only criticized them in terms of the degree to which they satisfied good government criteria to a lesser degree than the court's own plan. ${ }^{14}$ Of course, none had the sanction of state law, and so no deference to another branch of government was required. ${ }^{15}$ The court-ordered plan was attacked by Republican legislators as a pro-Democratic gerrymander. ${ }^{16}$ For example, Pennsylvania House Speaker Mike Turzai, R-Allegheny, and Pennsylvania Senate President Pro Tempore Joe Scarnati, R-Jefferson, in a joint statement issued on February 20, 2018, condemned the Pennsylvania

\begin{abstract}
${ }^{12}$ Jonathan Lai and Liz Navratil, "SCOTUS Denies Pa. GOP Lawmakers' Attempt to Delay Drawing New Congressional Map, Philadelphia Inquirer (February 5, 2018).

${ }^{13}$ Professor Persily has written extensively about election law in general and redistricting in particular, and had previously served several times as a court-appointed special master in congressional redistricting litigation, drawing plans that were adopted by federal courts. On January 26, 2018, he had been hired to help the court evaluate submitted plans and, if needed, to provide options to the court for a congressional plan of its own.

${ }^{14}$ Describing the adopted plan, and comparing it to other proposed remedial plans, the Pennsylvania Supreme Court says:
\end{abstract}

It is composed of congressional districts which follow the traditional redistricting criteria of compactness, contiguity, equality of population, and respect for the integrity of political subdivisions. The Remedial Plan splits only 13 counties. Of those, four counties are split into three districts and nine are split into two districts. The parties, intervenors, and amici differ in how they calculate municipal and precinct splits, and, as noted earlier, the Legislative Respondents suggest that updated data on precinct and municipal boundaries does not exist. The Remedial Plan is superior or comparable to all plans submitted by the parties, the intervenors, and amici, by whichever Census-provided definition one employs (Minor Civil Divisions, Cities, Boroughs, Townships, and Census Places).

The compactness of the plan is superior or comparable to the other submissions, according to the Reock, Schwartzberg, Polsby-Popper, Population Polygon, and Minimum Convex Polygon measures described in the Court's January 26 Order. Here, too, the parties, intervenors, and amici disagree on the precise ways to calculate these measures, and some failed to deliver compactness scores with their submissions. By whichever calculation methodology employed, the Remedial Plan is superior or comparable. Finally, no district has more than a one-person difference in population from any other district, and, therefore, the Remedial Plan achieves the constitutional guarantee of one person, one vote.

We should, however, note that the court in its adopted plan pairs two Democratic incumbents in Philadelphia (though one, Rep. Brady, was already intending to retire), three others who are retiring (Reps. Meehan, Dent, Shuster), and the vacant incumbent seat in old district 18 with an incumbent now running for the Senate (Rep. Barletta). Its final order does not even bother to mention the consequences for incumbents of the adopted plan. Presumably this is because the 2011 plan was so tainted overall by what we might call "partisan greed" that no deference is required to the contorted lines in it that yielded those incumbencies. But, since the court says nothing about its reasons for not mentioning effects on incumbents, we can only guess.

${ }^{15}$ Except in the one person, one vote context, and even there, only for congressional plans, in viewing redistricting challenges, courts have generally taken the view that a plan need not be the "best possible" in order to be constitutional.

${ }^{16}$ It might seem as if a plan challenged by one side as diluting its voting strength would, if the gerrymandering were remedied, then lead invariably to a challenge by the other side to the remedial plan as simply a partisan gerrymander in the reverse direction. And we do expect that such challenges would be made, but we also expect that most would be found to be frivolous, and some never get to the courts simply because of the high cost of bringing this kind of litigation. Also, given court deference to the other branches of government, we expect that most remedial plans would be drawn by the legislature itself (except where the state has shifted from unified to divided party control after the original line drawing, as was the case in Pennsylvania). 
Supreme Court's map as simply an illegitimate power grab by judges who are Democrats. In the initial draft of this article, we included calculations of various frequently used statewide measures of partisan gerrymandering effects so as to be able to compare the four most important plans: the Republican Joint Plan, the Democratic governor's plan, the 2011 plan, and the plan adopted in 2018 by the Pennsylvania Supreme Court, and to assess the degree to which each might be considered a partisan gerrymander. ${ }^{17}$ We would simply note that, based upon these analyses, we concluded that the 2011 plan was, indeed, a blatant partisan gerrymander, that the Joint Plan was a "stealth gerrymander," 18 and we rejected the claim that the court-adopted plan was itself a partisan gerrymander, but in a pro-Democratic direction. ${ }^{19}$

\section{Outline of the article}

In the next section we review the expert evidence the Pennsylvania Court relied upon in $L W V$, looking toward its implications for the types of evidence that might be useful in future partisan gerrymandering challenges brought under state law. Here we argue that, although the ruling explicitly states that the failure to satisfy good government criteria to a degree that cannot be attributed to chance or to the nature of the electoral geography in the state is sufficient to demonstrate unconstitutionality under Pennsylvania law, we expect that a court's judgment of when such a failure is egregious enough to be unconstitutional will be affected by other types of evidence presented at trial. In particular, in Pennsylvania, the evidence developed in the lower court about the political consequences of the adopted plan persuaded the court majority that

the 2011 Plan was a partisan gerrymander and that this gerrymander was extreme and durable. It was designed to dilute the votes of those who in prior elections voted for the party not in power in order to give the party in power a lasting electoral advantage ... On this record, it is clear that the 2011 Plan violates Article I, Section 5, since a diluted vote is not an equal vote. (emphasis added) $)^{20}$

In the succeeding section we look at implications of $L W V$ for state and federal partisan gerrymandering jurisprudence. Here we compare how the Pennsylvania court evaluated partisan gerrymandering with how federal courts have proposed to do so. We begin this section with a discussion of the standards offered by the three-judge federal panels that found unconstitutional levels of partisan gerrymandering in plans in Wisconsin and North Carolina. Then we look to see how the discussion of partisan gerrymandering offered by the trial court and the Pennsylvania Supreme Court might be relevant to challenges in federal courts based on district-specific complaints - the type of complaint recently required by the U.S. Supreme Court.

${ }^{17}$ In addition, we also compared these plans with a number of proposed "good government" maps presented on various blogs or drawn by the present authors. However, for space reasons, these analyses have been completely eliminated from the present version of the essay-with the intent that they will eventually be integrated into a separate research note. Maps and shapefiles from the plans that we generated are available at $<$ https://github.com/jcervas/Can-State-Courts-Cure-PartisanGerrymandering $>$.

${ }^{18} \mathrm{~A}$ stealth gerrymander is defined in a Monkey Cage op-ed by Grofman and Cervas (2018) as one in which the plan, on its face, satisfies traditional districting criteria to a very reasonable degree but is nonetheless a carefully crafted egregious gerrymander. Because the court requested no information about partisan consequences, this left open the possibility that one or more of the parties would submit a "stealth gerrymander" as its proposed remedy - a possibility that Grofman and Cervas warned about. As they point out, "gerrymandering is like cancer: sometimes the signs are obvious" (e.g., suspicious lumps that are visible to the naked eye); "sometimes the signs are more or less invisible" (prostate cancer). They wrote: "Districts that are bizarrely drawn and unnecessarily fragment existing political boundaries such as townships and counties almost always indicate ... gerrymandering. But sometimes districts satisfy good government criteria on their face, and nonetheless have egregious partisan intent and effects."

${ }^{19} \mathrm{We}$ make a distinction between that which belongs to the realm of constitutional and statutory interpretation of voting rights issues that is the ultimate purview of the courts, and the measurement contributions to be made by social scientists to that legal decision-making, e.g., about how best to measure concepts such as compactness or racially polarized voting. The view taken by the Pennsylvania Supreme Court about what, under Pennsylvania state law, constitutes evidence for a partisan gerrymander is a legal judgment. Writing as a social scientist, one of us had offered a quite different perspective on how best to define and measure a partisan gerrymander (Grofman 2018a; Grofman and Gaddie 2017, 2018). And, in the light of the Supreme Court's decision in Gill v. Whitford, we think it quite likely that legal and social science perspectives on federal standards for partisan gerrymandering will diverge, with the former emphasizing district-specific findings and the latter emphasizing jurisdiction-wide findings-though we also see the potential for a Hegelian synthesis in which, for example, we might look at statewide violations for which there are district-specific remedies.

${ }^{20}$ One common sense definition of partisan gerrymandering is that a partisan gerrymander places unequal burdens on voters' opportunity to elect their representatives based on the party with which they associate. A term often used in conjunction with gerrymandering is vote dilution ( $c f$. Grofman 2018a). 
In our concluding discussion we review the key lessons to be learned from the Pennsylvania case. First, in light of the electoral geography of a state such as Pennsylvania, in which Democratic voting strength is more concentrated than Republican voting strength, we briefly examine the trade-offs between a reliance on good government criteria and prospects for political fairness. Next, we consider the practical question of how the Pennsylvania decision might affect the strategic calculations of partisan actors involved in line drawing after the 2020 Census, arguing that what we have referred to as stealth gerrymandering will become more common, and blatant partisan gerrymandering less so (Grofman and Cervas 2018). Finally, we consider in more detail the implications of $L W V$ for the future of challenges to partisan gerrymandering that would be brought in state courts, under state rather than federal law. Here we argue that, in light of where the U.S. Supreme Court seems to be going with respect to federal standards for partisan gerrymandering, we should expect more challenges to partisan gerrymanders to be brought in state court, taking their inspiration from the $L W V$ opinion and the state constitutional provision it drew upon for its legal conclusions.

\section{EXAMINING THE EXPERT WITNESS TESTIMONY IN $L W V$ AND HOW IT WAS EVALUATED BY THE COURT}

Now we turn to the expert witness in the case presented at trial. As noted earlier, although the violation of good government criteria in the plan as a whole was found to be sufficient to establish a constitutional violation in Pennsylvania, we believe the evidence demonstrating partisan gerrymandering effects and intent, including district-specific evidence of packing and cracking of Democratic voting strength via manipulation of district boundaries, was also relevant to the Pennsylvania Supreme Court's decision in $L W V$.

The goal of our discussion of expert witness testimony is to show how Pennsylvania judges reacted, both positively and negatively, to expert witness testimony about measurement of partisan gerrymandering effects and claims about partisan intent, rather than to continue the recent expert vs. expert debate about the merits and demerits of particular measures. Given the potential importance of $L W V$ as an inspiration for future state court decisions about partisan gerrymandering in other states, it is important to look closely at the nature of the expert witness evidence referenced by the Pennsylvania Court, and how they did or did not give particular testimony credence. ${ }^{21}$

We frame our discussion of the expert witness testimony in the case in a theoretical framework that compares and contrasts the evidence for partisan gerrymandering effects or intent. We consider five aspects of gerrymandering about which evidence was presented at trial: (1) violation of good government criteria to a degree that exceeded chance, (2) packing and cracking of minority party voting strength, (3) severe disparate partisan impact, to a degree that exceeded chance, after taking into account the electoral geography, (4) durability of the 2011 plan's partisan effects, and (5) intent to discriminate. In our discussion of the judicial treatment of expert witness testimony in Pennsylvania we focus almost entirely on Judge Brobson's "Magistrate's Recommended Findings of Fact and Conclusions of Law," since the Pennsylvania Supreme Court relied on the analyses of the expert testimony offered by the trial court judge, even though it rejected the lower court's legal conclusions.

\section{Violation of good government criteria to a degree that exceeded chance}

Using voting tabulation districts as building blocks, Professor Jowei Chen, testifying on behalf of plaintiffs, developed computer simulation results of plan features under two different sets of assumptions. The first, Set I, prioritized the traditional criteria in the following order: (1) equal population; (2) contiguity of districts; (3) minimization of counties split between districts; (4) minimization of municipality splits; and (5) compactness, under two different compactness measures ("Reock"

\footnotetext{
${ }^{21}$ The expert analyses offered in the Pennsylvania Supreme Court case are mostly jurisdiction-wide, so the standard approaches to measuring partisan gerrymandering effects of this type discussed later in this essay, and evidence about the statistical significance of their estimated effects, almost certainly retain relevance for future state court cases that draw on the Pennsylvania Supreme Court decision for inspiration, even if their relevance for federal district-specific partisan gerrymandering challenges now seems very limited.
} 
and "Popper-Polsby"). ${ }^{22}$ The second, Set II, added to these criteria the requirement that at least 17 of the incumbents were placed in separate districts. Set I simulated plans split 11 to 16 counties and split 40-58 municipalities, whereas the 2011 plan split 28 counties and 68 municipalities. Professor Chen took this as demonstration that the 2011 plan could not plausibly have emerged from a districting process that prioritizes traditional districting criteria. ${ }^{23}$

What Professor Chen is doing is classical statistical null hypothesis testing. He posits that the legislature was following traditional districting criteria regarding minimizing county splits and then checks to see if the county and municipal splits in the 2011 plan are compatible with this null hypothesis. To do so, he generates a distribution of plans drawn with this good government criteria in mind and shows that the observed plan is so far out on the tail of this distribution that we can reject the claim that it was drawn with these criteria in mind. Professor Chen does essentially the same thing vis-à-vis compactness, showing that the 2011 plan is significantly less compact than every single one of the Set I simulated districting plans, and we can thus safely reject the null hypothesis that it was drawn with compactness considerations in mind.

Professor Chen's demonstration was taken as having provided a statistical demonstration that the 2011 plan cannot be directed at complying with traditional redistricting requirements, and the court held that such a statistical finding is sufficient to establish that it violates the "Free and Equal Elections Clause." ${ }^{24}$ Of course, as we have noted above, we suspect that the evidence offered by plaintiffs might not have defeated a motion for dismissal had it not also included evidence that much more directly bore on the partisan effects and intent of the plan. In particular, as noted previously, the court's final order refers to the 2011 plan as a "severe and durable" partisan gerrymander, and Judge Brobson's opinion in the Commonwealth Court (the trial court) includes in his findings of fact a plethora of evidence that went well beyond its failure to satisfy traditional districting criteria to demonstrate that the plan had the indicia of a partisan gerrymander.

\section{Packing and cracking of minority party voting} strength and other forms of geographic manipulation

"Cracking" and "packing" are two of the fundamental tools of gerrymandering. Packing refers to con- centration of the other party's electoral strength so that it wins some districts by lopsided margins, thus leaving its voting strength inefficiently distributed. Cracking refers to dispersal of a party's electoral strength to maximize the number of districts in which it controls a majority. Packing and cracking are basically two sides of the same coin, but, given the potential for complex ripple effects, it may not always be possible to match a district that has been packed with another district (or set of districts) that has been cracked. We would also emphasize that there is no single magic percentage above which constitutes packing, and no single magic percentage below which constitutes cracking. Analyses must be context specific.

There are two ways in which attempts at packing and cracking might be demonstrated. The first and most straightforward involves examination of actual geographic boundaries of individual districts and a review of the districting choices that were made in creating those districts, i.e., a district by district analysis. The second involves use of some proposed statistical measure of overall packing and cracking. In this subsection we limit ourselves to the first of these; we discuss the efficiency gap as a statistical measure of packing and cracking in a later subsection.

Another form of geographic manipulation when redistricting takes place is disparate pairing, where incumbents of the minority party are more likely to be paired with another incumbent of their own party than is true for incumbents of the

\footnotetext{
${ }^{22}$ One of these can be taken to be a measure of what Niemi et al. (1990) refer to as an areal measure of compactness, i.e., how close a district is to a circle, as judged by comparing the area of the district to the area of a circumscribing circle; the other can be taken as a measure of what Niemi et al. (1990) refer to as a perimeter measure of compactness, i.e., how irregular is the perimeter of the district, to be determined by comparing the area of the district to the area of a circle whose circumference is equal to the district perimeter. See further discussion later in the text.

${ }^{23}$ Recommended Findings of Fact and Conclusions of Law, No. 261 M.D. 2017 (slip op., pp. 58-59).

${ }^{24}$ Chen's simulation approach has been critiqued in the recent literature on redistricting, mostly because of the limited number of computer generated maps it is based upon, and because of disagreements about an appropriate sampling frame. Here, however, we limit ourselves to discussion of the criticisms of his approach that were presented at trial by Wendy Tam Cho as rebuttal evidence and referenced in the trial court opinion. These focused mainly on the aspects of his simulation that dealt with expected partisan outcomes. (See discussion of how the trial court viewed Professor Cho's testimony below.)
} 
majority party, or where there are pairings of incumbents of opposite parties that are done in such a way that the incumbent from the minority party is more likely to lose. Because Pennsylvania lost a congressional seat in the 2010 reapportionment, one pairing of incumbents was necessary unless there was a retirement. The Republican legislature and governor chose to pair two Democratic incumbents (and no Republicans) in the 2011 plan. ${ }^{25}$ Yet another form of geographic manipulation is what one of the present authors has previously labeled kidnapping, where incumbents of the minority party are more likely than incumbents of the majority party to see the set of voters within their districts substantially changed in a way that reduces the minority party incumbent's likelihood of reelection, even though they might not be paired with any other incumbent(s).

The key expert witness for plaintiffs on the plan features identified above was Professor John J. Kennedy. While Professor Kennedy discussed indicators of partisan support in the various "pieces" that made up a given district, to demonstrate either packing or cracking, much of his analysis dealt with the strange shapes of many of the districts in the 2011 plan and/or with the failure of districts to reflect common communities of interest. Illustrative is his discussion of removal of Democratic voting strength from Pennsylvania's 6th Congressional District (CD) to make the district more Republican. As summarized by the trial court (Recommended Findings of Fact and Conclusions of Law, slip op., p. 74):

Dr. Kennedy explained that the 6th Congressional District, which is likened by some as resembling the State of Florida with a more jagged and elongated panhandle, includes communities in southern Chester County, western Montgomery County, Berks County, and Lebanon County. When asked whether there is anything that unites these communities other than all being located within the 6th Congressional District, Dr. Kennedy opined that they are all separate and distinct communities of interest that have been combined into the 6th Congressional District and not maintained as a whole. Dr. Kennedy also explained that the City of Reading, which is the county seat of Berks County, has been carved out of the 6th Congressional District. Dr. Kennedy opined that this changes the partisan makeup and performance of the 6th Congressional District considerably because the City of Reading is a very Democratic city.
Relatedly, Professor Kennedy pointed out that the City of Reading and another Democratic area, the City of Coatesville, were placed in with heavily Republican areas in the 16th CD (based in Amish country), with a "net political effect of diluting Democratic precincts and Democratic performance in Reading and Coatesville" (Recommended Findings of Fact and Conclusions of Law, slip op., p. 75).

Perhaps the most compelling of Professor Kennedy's dissections of district boundaries was his discussion of CD7. The trial court (Recommended Findings of Fact and Conclusions of Law, slip op., p. 74) summarized this discussion as follows:

[T] 7 7th Congressional District, which is commonly referred to as the "Goofy Kicking Donald Duck" district, has become famous as one of the most gerrymandered districts in the country. Dr. Kennedy described the 7th Congressional District as essentially 2 districts (an eastern district and a western district) that are held together at 2 locations: (1) a tract of land that is roughly the length of 2 football fields and contains a medical facility; and (2) a Creed's Seafood \& Steaks in King of Prussia. Dr. Kennedy also indicated that the 7th Congressional District contains 26 split municipalities.

\section{Statistical measures of severe disparate partisan impact}

There were three different measures of alleged disparate impact used in expert witness testimony: (a) comparison with simulation results, (b) meanmedian gap, and (c) the efficiency gap. ${ }^{26}$ In looking

\footnotetext{
${ }^{25}$ Professor Kennedy used the term kidnapping to refer to what we have called same party "pairing." Since the latter term is the more common one in the redistricting literature, it is the one we use here. As noted below, we use the term "kidnapping" with a different meaning, one related to the removal of supportive voters and their replacement by less supportive others.

${ }^{26}$ Evidence about a fourth standard metric of partisan disparity, partisan bias (see, e.g., Grofman and King 2007), which is arguably the approach which had previously attracted the most attention, including favorable references to it in previous Supreme Court gerrymandering cases as a potential component of a partisan gerrymandering test, was not, as far as we are aware, presented at trial. That was unfortunate for various reasons, including the fact that the seats-votes curve on which it is based allows us to separate out the idea of responsiveness/swing ratio (which is at the heart of the efficiency gap approach) from bias.
} 
at measures of partisan asymmetry, we want to emphasize a very important point. Just as students in elementary statistics classes are taught that there are different features of a distribution, e.g., mean, variance, skewness, kurtosis, and are also taught that no single number allows us to fully capture the features of a distribution, although some, such as the mean and variance, capture features that are commonly regarded as of the greatest interest, there is no single "magic number" regarding an analysis of gerrymandering. While having multiple measures of disparate impact that reinforce one another can be very helpful, we need to distinguish the magnitude of disparate effect in some particular election and the likely durability of the disparity.

Comparison with simulation results of partisan outcomes under good government plans. In examining the statistical likelihood that partisan outcome disparities as extreme as those observed under the challenged 2011 plan could have occurred by chance alone, each of the plaintiff's expert witnesses on this issue (Professor Jowei Chen, a political scientist, and Professor Wesley Pegden, a mathematician) offered distinctive computer simulation methods.

Professor Chen used essentially the same method for assessing the extremism of the partisan effects of the 2011 plan as he had used for assessing the degree to which the 2011 plan could have been said to satisfy good government criteria. He wrote a computer program to create a large number of good government plans and then evaluated the partisan consequences of each of those plans, based on a simple dichotomous measure, namely, what was the party with the majority of projected votes in each of the districts and how many seats for each party did such a projection yield for the delegation as a whole. In one of his algorithms he paid no attention to incumbency protection; in the second he did. Then he compared the $13 \mathrm{R}-5 \mathrm{D}$ outcome in the actual plan with the distribution of delegation wide partisan outcomes in the simulations. ${ }^{27} \mathrm{He}$ found "that the 2011 Plan creates several more congressional voting districts with partisan performance calculations favoring Republicans, which resulted in several more Republican seats than what is generally achievable under a map drawing process respecting nonpartisan, traditional districting criteria" (Recommended Findings of Fact and Conclusions of Law, slip op., p. 62).
Repeating this analysis with a simulation that took incumbency protection into account, Professor Chen showed that plans that were similar to the 2011 districting plans in terms of incumbency protection could achieve "this protection at the cost of only a small increase in split counties and a modest decrease in district compactness" from plans drawn without taking incumbency protection into account. (Recommended Findings of Fact and Conclusions of Law, slip op., p. 66). For example, his second simulation "split between 12 to 19 counties, with the vast majority splitting 15,16 , or 17 counties, whereas the 2011 Plan split 28 counties" out of 68 total counties (Recommended Findings of Fact and Conclusions of Law, slip op., p. 66).

Professor Chen also took into account racial vote dilution concerns by restricting his analyses to the 259 of his 500 simulated plans that contained a congressional district in it with at least a 56.8\% African American voting-age population (VAP) - the African American VAP share in the single majority minority district in the 2011 plan. Among these plans, "not a single simulated districting plan remotely came close to creating 13 congressional voting districts with partisan performance calculations favoring Republicans" (Recommended Findings of Fact and Conclusions of Law, slip op., p. 69).

Professor Pegden asked a different question than Professor Chen. Professor Chen asked, "How does the 2011 plan compare to good government plans in terms of its partisan disparity?" Professor Pegden asked: "If you were to generate plans that were as good as the 2011 plan vis-à-vis good government criteria, how likely would such plans be to have the extreme partisan disparity (13 to 5) found in the challenged plan?" Thus, rather than generating plans from "scratch," i.e., from de novo line drawing, Professor Pegden started by taking the actual 2011 plan, and had his computer program make incremental changes in its boundaries to create a new plan in a fashion intended to minimize changes in overall plan compactness. By repeating this process many times, with random starting points for the changes, he was able to create a multiplicity of plans whose good government properties were similar to those of the challenged plan with respect to

\footnotetext{
${ }^{27} \mathrm{He}$ also used his simulation results to look at the mean minus median gap, but we will discuss that aspect of his findings in the section on partisan asymmetry measures below.
} 
compactness. Moreover, although county and city cuts were not being taken into account, in fact, the plans that were created were similar in those respects to the challenged plan that served as its base.

Once we have established the simple fact of a discrepancy between partisan vote share and partisan seat share, Professor Pegden proposed two statistical tests for the existence of partisan gerrymandering. First, the overwhelming majority of the alternative plans should have less extreme partisan imbalance than the challenged plan. Second, because he was creating new plans in an explicitly incremental fashion, Professor Pegden could ask whether or not the changes that were made tended to reduce the level of disparate impact. ${ }^{28}$ In his view, if small random perturbations in a plan made it less extreme in its partisan consequences, that would suggest that the plan had been a carefully crafted gerrymander. Professor Pegden found that both his tests demonstrated partisan gerrymandering. Not only was the first test met, in that "The 2011 Plan exhibits more partisan bias than roughly $99.999999 \%$ of the simulated possible alternative districting plans created by his computer algorithm," but he also found that "small random changes to the 2011 Plan rapidly decrease the partisan bias of the 2011 Plan" (Recommended Findings of Fact and Conclusions of Law, slip op., pp. 82-83).

The algorithmic approaches taken by both Professor Chen and Professor Pegden were challenged by defendant's expert Professor Wendy Tam Cho. Chen's algorithm was criticized as deterministic and not probabilistic, but that assertion was rebutted by Chen. Pegden's algorithm was criticized, inter alia, for its failure to take into account municipal splits and incumbency protection. The trial court concluded that "Dr. Cho's testimony was not credible with regard to her criticisms of the algorithms used by Dr. Chen and Dr. Pegden, but credible with regard to her observation that Dr. Pegden's algorithm failed to avoid municipal splits and did not account for permissible incumbency protection" (Recommended Findings of Fact and Conclusions of Law, slip op., p. 91). It then went on to say "Dr. Cho's testimony does not lessen the weight given to Dr. Chen's testimony that adherence to (what he considers to be) traditional redistricting criteria does not explain the partisan bias of the 2011 Plan," and "Dr. Cho's testimony does not lessen the weight given to Dr. Pegden's conclusion that the 2011 Plan is an outlier when compared to maps with nearly identical population equality, contiguity, com- pactness, and number of county splits" (Recommended Findings of Fact and Conclusions of Law, slip op., p. 91). As we see it, the Chen and Pegden analyses, especially the former, offered the Pennsylvania Supreme Court the most nearly definitive statistical evidence about partisan gerrymandering, because they compare the level of disparate impact in the actual plan to other plans in a way that takes into account the actual electoral geography.

From our viewpoint, the most important feature of Professor Cho's criticisms of the work of Professor Chen and the work of Professor Pegden was that these were being attacked as methodologically flawed. Pointing out methodological flaws is a very important part of the process of doing science, and it can be especially important at trials where there is not a process of peer review of methods and analyses presented. It is always useful, however, to remember Wuffle's 4th Law of Political Science Methodology, "It is far easier to criticize than to do better" (Wuffle 2015). The failure of Professor Cho to do analyses of her own that added the features that she criticized as being missing from the analyses of plaintiff's experts made her testimony less compelling than it otherwise might have been. ${ }^{29}$

In order to simulate partisan outcomes under alternative maps, as was done by both Professor Chen and Professor Pegden, we need to be able to make projections into districts in which no congressional election has been held. To do this it is necessary to have past election data or some other measure of partisan propensities available to use at the same (low) level of geography that was used to create the plans. ${ }^{30}$ There are three main

\footnotetext{
${ }^{28}$ Here we should note that we have reversed the order of presentation of Professor Pegden's test, since we regard the first of these the simpler one, and as much more important. However, we also believe that some strongly gerrymandered plans can be created that will pass both tests-ones where districts for both parties are safe, but the minority party districts are even safer than those of the majority party ( $c f$. Owen and Grofman 1988). But, since we have not actually done such tests using Professor Pegden's algorithm, that can only be a conjecture.

${ }^{29}$ One of the present authors has a great deal of sympathy for the position Professor Cho found herself in, namely being brought in as a purely rebuttal witness, probably with less time than needed to do original analyses of her own, because he has been in that uncomfortable situation himself on several occasions.

${ }^{30}$ This is true whether the plans in question are created via computer simulation algorithm or created "by hand" by parties to the case of intervenors, or by interest groups, or by members of the public simply interested in offering an alternative map.
} 
issues: first, should election data, registration data, or some combination of the two serve as the basis for the projection. Second, which election data should be used for the projection: statewide bottom of the ticket contests, top of the ticket statewide contests, presidential contests contests for elections of the same type as are under challenge in the case by pooling election data across units to create "simulated" constituencies, or some composite set of statewide elections? Third, should other variables such as home ownership, racial composition of the district, incumbency factors, or trends be included in the model? Our view is that there is no correct a priori answer to these questions. Rather, experts can offer predictive models, and the most useful test of those models is quite simply: Do they predict (past) elections? $?^{31}$

Both Professor Chen and Professor Pegden made use of political outcome projections to evaluate the partisan consequences of their simulated plans. Professor Pegden used the 2010 Pennsylvania U.S. Senate race between Pat Toomey and Joe Sestak, "because it was a statewide race, there was no incumbent in the race, and it was among the most recent data available to mapmakers when drawing the 2011 Plan." (Recommended Findings of Fact and Conclusions of Law, slip op., p. 80). Professor Chen used "the aggregated results of the 2008-2010 statewide elections" (Recommended Findings of Fact and Conclusions of Law, slip op., p. 63).

Testifying for Defendants, Professor Nolan McCarty's principal criticism of the simulation methodologies used was that the estimates of partisan outcomes they produced were inadequate. His analyses of the 2011 plan, based on a set of aggregated earlier elections used to create a partisan vote index (PVI), ${ }^{32}$ suggested that "Democrats should have won 8 seats under the 2011 Plan, and that their failure to do so was based upon other outcomes, such as candidate quality, incumbency, spending, national tides, and trends within the electorate" (Recommended Findings of Fact and Conclusions of Law, slip op., p. 93). However, when Professor Chen's rebuttal demonstrated that his predictive model yielded 54 of 54 correct predictions over the elections of 2012, 2014, and 2016, while Professor McCarty made predictions that were contradicted by actual election results and highlighted the importance of factors that were not actually incorporated into his model, the trial court took an Occam's Razor approach to Professor McCarty's testimony. "The Court finds Dr. McCarty's testimony not credible with regard to criticism of Dr. Chen's report, as the methodology employed by Dr. Chen to calculate partisan performance appears to have been a reliable predictor of election outcomes in Pennsylvania since the enactment of the 2011 Plan" (Recommended Findings of Fact and Conclusions of Law, slip op., p. 93).

Mean-median gap. In addition to directly calculating expected outcomes, Professor Chen used his simulations to provide statistical comparisons of mean minus median values. The mean minus median test is a well-known simple measure of asymmetry, closely related to skewness. Its use has recently been advocated as a test for partisan gerrymandering (McDonald and Best 2015, cf. Wang 2016a). When we report the two-party vote shares of a given party, if the mean value of all districts is much larger than its median value, this indicates that party vote shares are not symmetrically distributed (for a normal distribution the mean and the median are identical) and, more particularly, the party in this situation is disadvantaged. The larger the gap, the greater the partisan asymmetry, since the value at the median district tells you which party will control the majority of the seats. "Dr. Chen opined that the skew of the mean-median gap in the 2011 Plan created a significant advantage for Republicans by giving them stronger control over the median district" (Recommended Findings of Fact and Conclusions of Law, slip op., p. 64). Chen found that the range of skew in his simulations that did not take incumbency into account was "always much smaller than the 5.9\% meanmedian gap observed in the 2011 Plan," and he "concluded, based on his analysis of the meanmedian that the 2011 Plan ... created an extreme partisan outcome that cannot be explained by Pennsylvania's voter geography or by any of the traditional districting criteria" (Recommended

\footnotetext{
${ }^{31}$ But "Occam's Razor" also suggests that simpler models are, ceteris paribus, often better, lest we "overfit" historical data in a way that will not generalize.

${ }^{32}$ The Cook PVI is based on past presidential voting patterns and is used (at the state or congressional level) to measure relative partisan performance compared to the nation as a whole.
} 
Findings of Fact and Conclusions of Law, slip op., p. 65). Moreover, Chen's further analyses, using simulations that were attuned to the requirement of preserving incumbencies, reinforced this conclusion.

Efficiency gap. Professor Christopher Warshaw presented testimony at trial about the efficiency gap. ${ }^{33}$ "The efficiency gap is defined as the difference between the parties' respective 'wasted votes,' divided by the total number of votes cast in the election. In calculating the efficiency gap, all of the losing party's votes are wasted if it loses the election. As to the winning party, the wasted votes are those above the $50 \%$ plus 1 vote required to win" (Recommended Findings of Fact and Conclusions of Law, slip op., p. 85). Here the measure of cracking is taken to be the measure of wasted votes given above for the losing party, and the measure of packing is taken to be the measure of wasted votes given above for the winning party. The sign on the efficiency gap will be positive when a given party has a higher proportion of seats than its proportion of votes. Professor Warshaw drew comparisons between its values in elections held under the 2011 congressional map versus elections held under previous congressional maps, and comparisons with efficiency gap values from other states. He concluded that efficiency gap measures under the 2011 plan were outliers both with respect to congressional elections held within the state under plans adopted in previous decades and in comparison to current efficiency gap values in other states.

In our view, the efficiency gap is the least useful of the several approaches to measuring jurisdictionwide disparate impact we discuss in this subsection since it is the furthest from the face meaning of that concept. While it is commonly presented as a measure of wasted votes in terms of vote efficiency lost to packing and cracking, as was done by Professor Warshaw in his testimony, this is somewhat misleading. As the inventor of the measure, Eric McGhee $(2017,6)$ correctly observes

The EG [efficiency gap] may be framed in terms of wasted votes, but it translates mathematically into a particular relationship between vote share and seat share. The EG will be zero as long as a plan's seat margin (the seat share minus 50 percent) is twice its vote margin (the vote share minus 50 percent). In other words, the ideal plan's seats-votes curve should pass through the
$(50,50)$ point and have a responsiveness of two. This commitment to a specific responsiveness is a critical difference from both symmetry and the MMD [mean median difference]. Both of those measures allow any responsiveness so long as half the votes lead to half the seats.

This description of the efficiency gap by one of its leading proponents is sufficient to demonstrate its limited direct legal relevance in the context of partisan gerrymandering at the jurisdiction-wide level. While the idea that symmetry of treatment requires that both parties be treated alike is key to all the measures of disparate impact, the efficiency gap's requirement that the ideal responsive level is two has no obvious legal justification. What it says, roughly speaking, is that the ratio of the dominant party's seat share and fifty percent and the dominant party's vote share and fifty percent should, in a perfectly fair world, be exactly two. But, it is a responsiveness value of one that indicates perfect proportionality of votes and seats! ${ }^{34}$

And, if partisan vote shares were normally distributed, with a mean of $50 \%$ and a standard deviation we would expect for a binomial distribution, for example, the expected responsiveness would be

\footnotetext{
${ }^{33}$ While his primary testimony was about the efficiency gap, Professor Warshaw also presented testimony more directly about partisan asymmetry. In particular, he pointed out that "in 2012, Republican candidates won only $49 \%$ of the statewide vote, but they won 13 of 18 (72\%) of Pennsylvania's congressional seats." Of course, a mere disparity between vote share and seat share, standing alone, is not enough to demonstrate partisan gerrymandering, much less partisan gerrymandering that rises to the level of unconstitutionality. But that fact was only a small part of the evidence for partisan gerrymandering produced at trial.

${ }^{34}$ Drawing "good government lines" that do not compensate for biases imposed by electoral geography, do not impose a requirement for proportionality. However, even a court-drawn plan that attempted to satisfy good government criteria and consider electoral geography is unlikely to result in proportional representation since single member districts tend to disadvantage the minority party relative to its share of the vote (see, e.g., Grofman 1982). Also, as noted above, while it might seem that the efficiency gap standard involves a requirement for proportionality, if we take proportionality to be defined as "a votes-seats slope coefficient of one, with zero bias" (i.e., the equivalent of a zero intercept), then the efficiency gap should not be seen as requiring proportionality, but rather be viewed as an attempt to restrict the scope of gerrymandering disproportionality by imposing a requirement that the slope of the votesseats curve should not be much greater than 2. As discussed in Grofman and King (2007), symmetry and proportionality are distinct concepts, even though a votes/seats slope of one with zero bias is both proportional and symmetric.
} 
something like three, a la the famous cube law (see, e.g., Kendall and Stuart 1950, see also Theil 1970). Moreover, the responsiveness level in the plan is tied to the number of highly competitive seats, and so, if we increase the number of highly competitive districts, this increase may (depending upon the nature of the partisan vote distribution) lead to a higher efficiency gap value. Thus, to the extent that having competitive districts is viewed as desirable then, for any given level of partisan bias, having a responsiveness level higher than two, and thus a non-zero efficiency gap, is also desirable. Yet reliance on the efficiency gap treats all higher levels of responsiveness as legally suspect. ${ }^{35}$ The potentially inappropriate treatment of competitive districts by the efficiency gap measure was noted by the trial judge, who asserted as a "lingering concern" (Recommended Findings of Fact and Conclusions of Law, slip op., p. 89) that

[T]he efficiency gap devalues competitive elections. Specifically, if a "fair" district is one in which the Republican and Democratic candidates have a roughly equal chance of prevailing in the election, a close contest will yield a substantial efficiency gap in favor of the prevailing party. In this regard, the efficiency gap treats a "fair" and competitive district as unfair and possibly unconstitutionally gerrymandered. ${ }^{36}$

Its treatment of competitive districts was not the only complaint the trial judge had about the efficiency gap. He asserted that the efficiency gap "does not take into account some relevant considerations, such as quality of candidates, incumbency advantage, and voter turnout" (Recommended Findings of Fact and Conclusions of Law, slip op., p. 89).

The factors pointed by Commonwealth Court Judge Brobson can indeed affect election outcomes, and thus can affect any measure that uses election results as input. But how important are these factors? Here, as with Judge Brobson's similar criticisms of other measures, there is a legal issue about burden shifting. At what point does the evidence for extreme partisan gerrymandering become sufficiently clear and compelling that it now becomes the responsibility of the defendant jurisdiction to show, by the analyses of their own experts, that legitimate factors not taken into account in the analyses presented by plaintiffs can explain the patterns of alleged gerrymandering? No single analysis can do everything, but experts must present evidence of partisan gerrymandering that stands up to alternative specifications and hypothetical complications. Furthermore, with respect to incumbency, there is a chicken and egg issue since the creation of a gerrymandered plan that favors the redistricting party's candidates will necessarily result in more elected officials of that party who benefit from the advantage of incumbency. Similarly, districts tilted toward one party reduce the incentives for strong candidates of the other party to run (Cox and Katz 1996; Abramowitz 1991). And the creation of districts that will be won by one party by lopsided margins reduces incentives for voter turnout (Grofman, Collet, and Griffin 1998; Blais 2006). Thus, treating these factors as independent of partisan gerrymandering effects seems to be misunderstanding the relevant causal paths.

\section{Durability of the 2011 plan's partisan effects}

In judging plan durability, it is important to recognize that, in principle, you can get different outcomes in competitive districts depending upon the nature of electoral tides, i.e., "good" years for Democrats (e.g., 2018) versus "good" years for Republicans (e.g., 2016). The simplest way to deal with this is to look at the actual (or projected) votes in years varying in the level of their partisan support and ask how resistant the outcomes in a given plan would be to perturbations in party support over these past elections. Another more general way to examine likely durability would be to look at the magnitude of all recent past inter-election

\footnotetext{
${ }^{35}$ A philosophical argument might be constructed as to why two was an "ideal" responsiveness level for state legislative districts, since, if there are "too many" competitive districts, then relatively small shifts in voter preferences may lead to dramatic changes in party seat share, and such violent oscillation in controlling majorities may make it hard to create consistent public policies. But such a debate is well beyond the scope of the present essay, and is not, as far as we are aware, already found in the literature, and it is hard to see how such a philosophical argument could be given legal underpinnings.

${ }^{36}$ Because we find this to be a plausible objection, and because we believe that a district specific analysis of what level of minority voting strength constitutes packing or cracking is required, rather than automatically counting any percentage above 50 percent as packing and any percentage below 50 percent as cracking, we also have grave doubts about the applicability of the efficiency gap approach to a showing that any given district is an unconstitutional gerrymander.
} 
shifts in two party vote shares at the state level and look at the changes in district outcomes in a given plan that would result were such shifts occurring in each district. Here we would look at the directionality of previous shifts and either the mean or maximum value previously observed. While we do not believe that this type of evidence was presented at trial in this case, the fact that three elections had already been conducted under the plan vitiated the need for direct examination of inter-election shifts. Quite simply, the fact that the outcomes had been 13R-5D in three consecutive elections, regardless of the partisan tides in those years, demonstrated the durability of the 2011 plan's egregiously disparate partisan effects in the existing political climate in Pennsylvania.

Ceteris paribus, districting effects can be expected to vary substantially over the course of a decade only if there are a substantial number of competitive seats. In the modern era of data rich computer-based redistricting, and highly polarized voting patterns, skillful gerrymandering can use the combination of packing and cracking gerrymandering techniques to eliminate the possibility of meaningful competition for most of the districts. By largely eliminating competitive districts, it is possible to freeze in place outcomes that will be more or less unchanged over the course of a decade, in a fashion that is largely independent of changes in voter preferences. Thus, absent a wave election, one party's partisan control over most districts, with concomitant control of a legislative chamber or a congressional delegation as a whole, can be maintained. As Keith Gaddie has pointed out, this lack of responsiveness punishes not just supporters of the disadvantaged party, but also punishes swing voters, since they find themselves unable to affect outcomes even when their own partisan preferences have shifted. ${ }^{37}$

Line drawers are now more knowledgeable about the need to avoid drawing a dummymander (a plan drawn by one party that ends up benefiting the other party when electoral tides shift) of the sort warned against by Grofman and Brunell (2005), than they were in past decades, as that term, coined by Grofman, has become an increasingly familiar part of the redistricting lexicon. Line drawers also have gained more technical sophistication in mapping historical election data into proposed districts, and then checking to make sure that they do not make a dummymandering kind of mistake.
In general, to assess durability, information about the number of potential competitive seats in the plan is very relevant (cf. Brady and Grofman 1991), and should be viewed in conjunction with (historical) information about the magnitude and distribution of inter-election shifts. The commonsense idea is very simple. If we know the historical patterns in changes across elections, then we can see how many districts would be affected by changes in the vote share in districts in the challenged plan that are of the same order of magnitude as the inter-election shifts in vote shares we have seen in the jurisdiction in the past. If districts are drawn sufficiently non-competitive, but with one party's voting strength even more concentrated than that of the other party, uncertainty about future outcomes can be kept to a minimum, or eliminated entirely, and the preservation of partisan bias imposed by differential cracking and packing perpetuated. We can, in principle, have large-scale disparities in treatment that are likely to be fleeting, and large-scale disparities in treatment that can be expected to last an entire decade, but the same is also true for small-scale disparities. Magnitude and expected duration can be unrelated to one another, and thus each must be examined separately.

It is also well known that incumbents of a given party can run ahead of the party's support in statewide contests. For example, if you simply project President Trump's 2016 vote into the 2011 districts you would get six Democratic victories in 2016 as compared to the five Democratic congressional wins. We can explain that difference by the fact that Clinton won pluralities in two seats that Republican incumbents won, in districts 6 and 7, while Trump won the plurality in district 17 , which was won by the Democratic incumbent. Because of incumbency advantage effects, ${ }^{38}$ we might see a reduction in the seats minus votes gap for the major party in elections after the first election under a new plan if that first election results in the election of more incumbents of the dominant party. If we are

\footnotetext{
${ }^{37}$ Remarks at the Roundtable on Partisan Gerrymandering, Annual Meeting of the Midwest Political Science Association, Chicago, April 6, 2018.

${ }^{38}$ Looking at districts over time, incumbents generally run better than non-incumbents of their same party because incumbents, on average, have more developed campaign organizations, sources of funding, and better name recognition, among other advantages.
} 
trying to develop realistic predictions of future elections it might be important to take incumbency effects into account, but there are also good reasons to disregard those in computer simulations, since in simulations we want to look at potential plans as a tabula rasa.

\section{Intent to discriminate}

There are multiple ways to get at legislative intent. First, there might be smoking gun evidence in the form of public statements by legislators. Remarkably, such statements were made in the 2010 round because legislators regarded federal courts as paper tigers with respect to policing egregious partisan gerrymander due to the Supreme Court's repeated failure to enunciate a manageable standard for unconstitutionality (McGann et al. 2016). Second, there could be process-related evidence, e.g., secrecy of line drawing, exclusion of input from the minority party, irrelevance of public input, or evidence of instructions to line drawers that suggested a blatantly partisan process. Third, there could be indirect evidence of intent by assuming that any reasonable person could see the consequences of a plan (both partisan and "good government") and therefore must be purposive. Here, of course, we would need to distinguish purposively partisan effects of line drawing from consequences of natural gerrymandering.

\section{Overview of the expert witness evidence presented at trial}

As noted above, the trial court found many indicia of partisan gerrymandering, but declined as a matter of law to hold that these allowed it to formulate a manageable standard for when partisan gerrymandering rose beyond politics as usual to the level of unconstitutionality. Moreover, when experts (such as Professor Pegden or Professor Kennedy) offered an opinion on the "ultimate question of law"-i.e., whether the 2011 plan is an unconstitutional political gerrymander-that opinion was "disregarded" by the trial court (see, e.g., Recommended Findings of Fact and Conclusions of Law, slip op., p. 83).

As for going beyond the statistical facts to assert that these were indicia not merely of partisan gerrymandering but of unconstitutional partisan gerrymandering, we agree fully with the trial court that determination of the latter is a matter of legal judgment as to what is the appropriate standard of unconstitutionality. However, while courts must be the architects of manageable standards by deciding which features of a plan need to be examined as part of a test for unconstitutional partisan gerrymandering, we, like the Pennsylvania Supreme Court, believe the lower court was wrong to dismiss the findings of experts that various features of the plan (e.g., undue fragmentation of county boundaries) were so extreme that one could statistically rule out the likelihood that this feature of the plan could have been due to chance alone.

What expert witnesses can do is (a) provide the analytic framework and metrics that courts can draw upon in crafting legal standards, (b) provide case-specific measurements of the factors that courts come to regard as the relevant ones, and (c) provide analysis of the degree to which given features of a plan are extreme in statistical terms. Unlike the lower court, the Pennsylvania Supreme Court made use of expert witness testimony in exactly these ways, using not just common sense measurements such as the number of city or county cuts, but relying also on the results of expert witness use of analytic tools for measuring compactness, and statistical tools for determining when observed patterns in the data counted as statistical outliers, so as to craft a court-specified test to distinguish the legitimate use of legislative discretion from choices that were unconstitutional. Indeed, the Pennsylvania Supreme Court, in enunciating its own tests, explicitly identified evidence of the statistical significance of jurisdiction-wide effects to critical for its finding that the 2011 plan was a partisan gerrymander. ${ }^{39}$

In our view, the conclusions to be drawn from the evidence presented at trial are clear. You could get the 13R-5D outcomes observed in Pennsylvania in every election beginning in 2012 only with a really carefully designed pro-Republican gerrymander that, in Professor Chen's words, "subordinat[ed] traditional districting criteria in the drawing of

\footnotetext{
${ }^{39}$ The kind of two (or three) standard deviation test used by various expert witnesses in this case is compatible with federal court jurisprudence in areas of civil rights such as employment discrimination (e.g., Bazemore v. Friday, 478 U.S. 385, 398 402,1986 ), and racial discrimination in jury selection (e.g., Castaneda v. Partida, 430 U.S. 482, 492-95, 1977).
} 
congressional voting districts." In the words of the Pennsylvania Supreme Court, such a plan was an "extreme and durable" partisan gerrymander. The evidence provided by Professor Kennedy demonstrated district-specific instances of packing and cracking but the state-wide evidence is even more compelling proof of partisan gerrymandering. The evidence includes simulations showing that partisan goals must explain the extreme violations of good government criteria and the 13R-5D partisan outcomes, and the evidence that the 2011 plan's mean-median gap was a statistical outlier.

\section{COMPARING $L W V$ WITH RECENT FEDERAL PARTISAN GERRYMANDERING CASES}

\section{What does it take to comply with the Pennsylvania State Constitution?}

Under the standard for unconstitutionality laid down by the Pennsylvania Supreme Court, we see that: (a) although particular districts might be found to be particularly egregious, evidence of unconstitutional gerrymandering can be found in a plan as a whole; (b) evidence of purposeful discrimination was not necessary in order to find unconstitutionality; ${ }^{40}$ (c) evidence of discriminatory partisan effects was not necessary to show a violation; ${ }^{41}$ (d) evidence that a plan complied with good government criteria is almost certainly not sufficient to rule out a finding of unconstitutionality, even though a finding that a plan failed to comply with such criteria was sufficient to invalidate the plan, and (e) for statewide analyses, findings that results are statistically significant and cannot be explained by the electoral geography of the state or by chance are very important, perhaps even necessary.

Comparison of the LWV approach to that of federal judges in Wisconsin and North Carolina and to the recent remands of those decisions by the U.S. Supreme Court

The closest federal voting rights law parallel to the standard laid down by the Pennsylvania Supreme Court is "one person, one vote" case law. Under federal law, you do not need to show that malapportionment matters for any particular end, you just need to show it exists. Nor do you need to show that malapportionment was intentional. ${ }^{42}$ Now, in Pennsylvania, you do not need to show that violation of good government redistricting criteria had substantive political or racial consequences, or that it was intentional-all you need to show is that it gave you lines on a map that lack adequate legitimate justification in terms of traditional good government districting criteria. In contrast, the two federal courts that have struck down plans as unconstitutional partisan gerrymanders, in Wisconsin and North Carolina, have taken quite different approaches to what is needed to show unconstitutionality-ones requiring plaintiffs to establish extreme and durable partisan effects that were intentionally created. ${ }^{43}$

However, we would also emphasize one important parallel between the state court and the federal lower court approaches in the states where a gerrymandering plan was overturned. Federal lower courts that overturned plans as partisan gerrymanders rooted their opinions in a profound repugnance to egregious partisan gerrymandering and a belief that it violates the spirit of democracy. This idea is captured in the North Carolina majority opinion's assertion that "On its most fundamental level, partisan gerrymandering violates 'the core principle of republican government ... that the voters should choose their representatives, not the other way around.""44

\footnotetext{
${ }^{40}$ However, if we look at the Court's final order of February 18, 2018 , at p. 1, the court asserts that the 2011 plan "was designed to dilute the votes of those who in prior elections voted for the party not in power in order to give the party in power a lasting electoral advantage" (emphasis added).

${ }^{41}$ However, if we look at the Court's final order of February 18, 2018 , on p. 1, the court asserts that the 2011 plan was "a partisan gerrymander ... that was extreme and durable."

${ }^{42}$ But, since calculating malapportionment is a matter of fourth grade arithmetic, it is hard to see how any malapportionment found could not have been intended.

${ }^{43}$ Of course, we must also acknowledge that the Pennsylvania Supreme Court, in rejecting the 2011 plan, also characterized it as having "extreme and durable" partisan effects. But as the quote provided earlier demonstrates, the finding of its unconstitutionality did not rest on those partisan aspects of the 2011 congressional plan but instead on a blatant violation of good government criteria that was inexplicable by any legitimate considerations, and whose parameters could be characterized as statistical outliers.

${ }^{44}$ Common Cause v. Rucho, No. 1:16-CV-1026 (January 9, 2018), slip op. at p. 3 quoting Ariz. State Leg., 135 S. Ct. 2652, 2677.
} 
Now we turn to comparisons of the Pennsylvania decision with the requirement of a districtspecific approach enunciated by the U.S. Supreme Court in its remand back to the lower court in Gill $v$. Whitford. We believe that elements of the analyses in Pennsylvania are relevant to the Supreme Court's remand of the decision in Maryland that dealt with only a single congressional district, and could be relevant to any future federal districtspecific rulings, including new decisions in Wisconsin and elsewhere.

In Maryland, a preliminary injunction to stop the implementation of the challenged map because of alleged unconstitutionality in the drawing of CD6 was rejected by the trial court, ${ }^{45}$ in an opinion that looked toward a resolution of the constitutional issues when the Supreme Court decided Gill v. Whitford. In our view, the challenged district, Maryland CD6, while having issues both with respect to crisscrossing of existing political subunit boundaries and with respect to compactness, is not as "ugly" vis-à-vis compactness and other good government grounds as some of the districts that were not challenged in the case. Rather, the heart of the challenge to the district was that particular areas of the state were included in or excluded from CD6 entirely on partisan grounds, with one and only one motive, to change the partisan outcome in the challenged district. Essentially, the argument is that changes in a district that can be understood only as an exercise of unbridled partisan lust are ipso facto unconstitutional. This argument has much the same flavor as the Pennsylvania Supreme Court's view that plans that blatantly violated good government criteria with no legitimate justification were ipso facto unconstitutional under Pennsylvania state law.

There are, of course, two key differences. First, the Pennsylvania decision relied on criteria that did not require assessment of either partisan consequences or of partisan intent. ${ }^{46}$ Second, the Pennsylvania Supreme Court rejected an entire plan and relied on evidence from the plan as a whole, in addition to district-specific evidence. Nonetheless, evidence presented at trial in Pennsylvania by Professor Kennedy (and reviewed in part in the discussion of the expert witness testimony in that case presented earlier) addressed the partisan implications of boundary shifts for some of the districts in the Pennsylvania congressional plan with evidence that was very similar to that asserted in the Maryland case. This type of evidence appears fully compatible with the Supreme Court's new district-specific focus.

\section{LESSONS OF $L W V$ FOR THE FUTURE}

Does the requirement for districts to be drawn with respect to neutral (good government) principles penalize one party over the other?

Philadelphia, Pennsylvania, is overwhelmingly Democratic in voting. In particular, if you draw two congressional districts entirely within Philadelphia County, one of them is very likely to give Democratic candidates around $90 \%$ of the vote, and for sure, as long as both are wholly within the County, the average vote in the two will be around $80 \%$ Democratic no matter how you draw the two districts. There are no other equally large and geographically concentrated pockets of equivalently overwhelmingly Republican voting strength. Thus, more Democratic votes will naturally be wasted in Philadelphia than Republican votes will be wasted elsewhere in the state. Additional Democratic wasted votes come in heavily Democratic Allegheny County, the county in which the city of Pittsburgh is located.

One approach to defining gerrymandering is to define partisan gerrymandering as occurring when a districting plan penalizes members of the minority party in their ability to translate votes into seats compared to what might be expected from a plan drawn on the basis of what are often called good government principles, e.g., satisfying the one person, one vote standard, avoiding diluting the voting strength of protected racial or ethnic minority groups, minimizing unnecessary political subunit splits, and providing reasonably compact districts. This is the definition given in Grofman

\footnotetext{
${ }^{45}$ Benisek v. Lamone, Civ No. JKB-13-3233 (D. Md. August 24, 2017).

${ }^{46}$ Wang (2016b), among others, has analyzed the Maryland map at a jurisdiction-wide level, and found evidence of gerrymandering by Democrats. His results indicate that "[congressional] redistricting gained Democrats a one-seat advantage in 2012, a strong Democratic year, and that this advantage was retained in the national wave election of 2014 that swept dozens of Republicans into office in states outside Maryland” (Wang 2016b, 1314).
} 
(2018a). It defines partisan gerrymandering with respect to a baseline that is based both on the actual electoral geography and based on satisfying good government criteria for redistricting. It is also the basis for how Professor Chen created his simulations. Such a standard is different from a standard of "fairness" based on having some reasonable relationship between the proportion (or expected proportion) of congressional or legislative seats captured by a given party and that party's share (or expected share) of the statewide twoparty vote.

A "good government" plan may reflect what has sometimes been called a natural gerrymander, i.e., a discrepancy between a party's vote share and its seat share that can be attributed solely to the geographic distribution of a party's electoral support and not to any intentional partisan gerrymandering. In Pennsylvania, for the U.S. House of Representatives, our analyses (omitted for space reasons) suggest that, ceteris paribus, Republicans might pick up about a one seat advantage from "neutral" redistricting using good government criteria, so if the state is $50-50$ in partisan vote share, a "neutral" plan might not be $9 \mathrm{R}-$ 9D, but more like 10R-8D. ${ }^{47}$ However, because there are many many different plans that can be drawn according to good government principles, such good government plans would exhibit a range of potential expected outcomes. Professor Chen's analysis indicated that the expected partisan outcomes of the 2011 plan were outside this range. ${ }^{48}$ Our own analyses of the court-ordered 2018 plan (omitted for space reasons) finds that the 2018 plan falls well within this range.

Looking to the future: stealth gerrymandering, more likely; blatant gerrymandering, less likely

In the next decade of redistricting, Pennsylvania and any other states where the court takes the same approach to partisan gerrymandering as the Pennsylvania Supreme Court, it will simply not be possible to repeat the kind of obvious gerrymander vis-a-vis tortuous line and fragmentation of county and municipal boundaries. Moreover, even in states that lack the specific state constitutional provision relied on by the Pennsylvania Supreme Court, after the $L W V$ opinion demonstrated the vulnerability of plans to state court challenge, we expect that risk-averse legislators now may not want to take chances that their plan-carefully crafted gerrymander or not-will be struck down. Thus, we expect good government criteria to be adhered to more strictly in the 2020 round of redistricting than was the case in the 2010 round.

If plans are being evaluated solely on good government criteria it will make it more difficult but not impossible to create a partisan gerrymander. Imposing good government constraints is something like imposing a handicap in a horse race, it forces skillful gerrymanders to work harder to win. As A Wuffle (personal communication, April 1, 2017) has opined: "If there are no constraints on partisan gerrymandering imposed by good government standards rooted in geography, then it doesn't take a genius to gerrymander." ${ }^{49}$ But if such standards are imposed, we expect that sophisticated and egregious partisan gerrymandering operating within the constraints of satisfying good government criteria to a degree that is intended to forestall court intervention (what Grofman and Cervas (2018) call stealth gerrymandering) will replace readily visible gerrymandering.

Looking to the future: Where can we expect new statelaw based partisan gerrymandering challenges?

While the Pennsylvania court opinion is limited to Pennsylvania, and thus it might seem of only

\footnotetext{
${ }^{47}$ Chen and Rodden (2013) estimate this bias as about 1.45 seats (8\%).

${ }^{48}$ His analyses rebut any claim that the observed partisan effects of the 2011 plan could be attributed either to electoral geography or to chance.

${ }^{49} L W V$ offers hope that in some state courts, even stealth gerrymanders will not be invulnerable. The reason for this optimism is that while $L W V$ makes violation of good government criteria to a statistical level of extremeness a sufficient condition for a plan to be an unconstitutional partisan gerrymander, it does not make it a necessary condition. Those who wish to put limits on partisan gerrymandering can take heart from the Pennsylvania Supreme Court's finding that the 2011 congressional plan was an "extreme and durable" partisan gerrymander, even though that finding was apparently not directly relevant to the court's decision to strike down the plan as unconstitutional. Nonetheless, it is an open question as to whether the Pennsylvania Supreme Court would have struck down the proposed Republican remedy plan, the Joint Plan, that we view as a stealth gerrymander, had it, not the 2011 plan, been the one proposed in 2011 by a Republican legislature and a Republican governor and thus entitled to judicial deference. As we show in analyses omitted for space reasons, the Joint Plan scored remarkably higher on good government criteria than did the rejected 2011 plan, even if it did not score quite as well as the plan the court actually adopted in 2018 .
} 
limited importance, in footnote 71 of the opinion (slip op., pp.116-117), the court took what we regard as a rather unusual step. It issued what can only be called an invitation to other state courts to use the same logic it used to invalidate partisan gerrymanders in their own state. The court noted that there are 12 states whose constitutions contain election clauses identical to the Pennsylvania charter, requiring elections to be "free and equal": Arizona, Arkansas, Delaware, Illinois, Indiana, Kentucky, Oklahoma, South Dakota, Oregon, Tennessee, Washington, and Wyoming. ${ }^{50}$ However, only a handful of these states are ripe for partisan gerrymandering challenges-in that (ca. 2017) three lack unified party control of the state, two are single-district states, and some already have a commission drawing plans and, in others, indicia of gerrymandering are missing. Moreover, states like Maryland, Michigan, North Carolina, Ohio, and Wisconsin, often regarded as among the most pernicious partisan gerrymanders (see, e.g., Wang 2016a; Royden and Li 2017), are not included among the 13 states with a "free and equal" clause in their state constitution.

Nonetheless, in looking to the future, it is critical to note that a "free and equal" elections clause is not the only avenue state courts might use to attack partisan gerrymanders in the future. As University of Kentucky College of Law Professor Joshua Douglas has pointed out, virtually every state constitution protects voting rights more explicitly than the U.S. Constitution does. In addition to the 13 states that require elections to be "free and equal," an additional 13 have state constitutional provisions that require elections to be "free and open," and this clause could, in principle, be used in exactly the same way as the "free and equal" clause. 51 The potential for state constitutional language to be repurposed to address partisan gerrymandering is elaborated on in Elmendorf (2018). ${ }^{52}$ Ceteris paribus, Elmendorf (2018) views attacks in state courts on partisan gerrymandering as most likely to succeed when there are (1) express limitations on favoritism in districting, or (2) generally worded electoral guarantees and favorable education precedents. ${ }^{53}$ The first table in the online appendix to his 2018 article identifies the 22 states that meet one or both of these criteria. In addition to Pennsylvania, other states whose congressional plans have been labeled by many as partisan gerrymanders, e.g., Maryland,
Michigan, North Carolina, and Ohio, are among the 22. Wisconsin, however, is not.

We expect that the February 7, 2018, Pennsylvania decision will trigger future partisan gerrymandering challenges in some state courts, perhaps even quickly enough to potentially impact some elections in 2020. Given the Pennsylvania Supreme Court's willingness to determine that a plan as a whole was a severe and extreme gerrymander on the basis of the expert witness presented at trial in $L W V$, we also believe that, despite an expected rise in stealth gerrymandering, it will be easier in the future to prove partisan gerrymandering in state courts that adopt the Pennsylvania approach than is likely to be true under federal law. Of course, when it comes to litigation under such an approach (or under the approach offered in Elmendorf [2018] discussed in the footnote immediately above), courts will be forced to consider empirical evidence about whether the actual plan (or some particular district or districts) adequately satisfies the criteria that are seen as required. For example, the Pennsylvania Supreme Court reviewed the evidence and concluded, inter alia, that the challenged congressional plan as a whole failed to adequately preserve existing political subunit boundaries.

${ }^{50}$ In its Opinion, the Pennsylvania Supreme Court provided specific citations to each of these provisions - citations which we have not bothered to reproduce.

${ }^{51}$ We are indebted to Jonathan Lai of the Philadelphia Inquirer (personal communication, April 2018) for calling this information to our attention.

${ }^{52}$ The discussion of relevant state constitutional provisions found in Elmendorf (2018) did not come to our attention until after we had completed work on the initially submitted version of this article.

${ }^{53}$ Elmendorf (2018) offers some intriguing parallels between redistricting issues and issues about the right to adequate schooling, placing both under a new rubric of "representational adequacy." Elmendorf (2018) argues that one way to finesse the issue of partisan gerrymandering standards is to, instead, assert an "implied legislative duty to adopt a reasonable redistricting framework, including standards for the 'representational adequacy' of legislative maps. Legislatures, not courts, would craft the legally operative standards" (Elmendorf 2018, 1605). In his view, such a duty-based approach would "allow courts to find a constitutional violation without committing to a contestable standard of partisan fairness, and without drawing a contestable line between adequate and inadequate fairness." Such an approach shifts the demarcation burden from distinguishing constitutional from unconstitutional partisan gerrymanders to one in which courts must ensure that the legislature complies with the legislature's own standards - albeit standards that the court has determined to be reasonable ones; and it allows state courts a role in detecting and remedying partisan and other forms of gerrymandering that are tied to state rather than federal law. 
Determinations of similar issues were made by the Florida Supreme Court in 2012 when it rejected the Florida Senate plan as unconstitutional under the new provisions of the "Fair Districts Amendment" to the State Constitution, and in 2015, when it rejected certain Florida congressional districts as unconstitutional, though in the 2015 case violation of process criteria played an important role. But enforcement is key! Many state constitutions have long specified redistricting standards such as compactness or preservation of city and county boundaries (Grofman 1985), and enacted versions of redistricting bills may contain pious language about the criteria ostensibly used in the line drawing, but these criteria have in the past failed to actually constrain partisan gerrymandering.

\section{REFERENCES}

Abramowitz, Alan I. 1991. "Incumbency, Campaign Spending, and the Decline of Competition in U.S. House Elections." Journal of Politics 53(1): 34-56.

Ariz. State Legislature v. Ariz. Independent Redistricting Commission. 2015. 135 S. Ct. 2652.

Davis v. Bandemer. 1986. 478 U.S. 109.

Bazemore v. Friday. 1986. 478 U.S. 385.

Benisek v. Lamone. 2017. Civ No, JKB-13-3233 (D. Md. August 24).

Blais, André. 2006. "What Affects Voter Turnout?" Annual Review of Political Science 9(1): 111-125.

Brady, David W., and Bernard Grofman. 1991. "Sectional Differences in Partisan Bias and Electoral Responsiveness in US House Elections." British Journal of Political Science 21(2): 247-256.

Castaneda v. Partida. 1977. 430 U.S. 482.

Chen, Jowei, and Jonathan Rodden. 2013. "Unintentional Gerrymandering: Political Geography and Electoral Bias in Legislatures." Quarterly Journal of Political Science 8: 239-269.

Common Cause v. Rucho. 2018. No. 1:16-CV-1026 (M.D.N.C. January 9).

Cox, Gary W., and Jonathan N. Katz. 1996. "Why Did the Incumbency Advantage in U.S. House Elections Grow?" American Journal of Political Science 40(2): 478-497.

Elmendorf, Christopher S. 2018. "From Educational Adequacy to Representational Adequacy: A New Template for Legal Attacks on Partisan Gerrymanders." William \& Mary Law Review 59(5): 1601-1680.

Gill v. Whitford. 2018. 138 S. Ct. 1916.

Grofman, Bernard. 1982. "For Single Member Districts, Random Is Not Equal.” In Representation and Redistricting Issues, eds. Bernard Grofman, Arend Lijphart, Robert McKay, and Howard Scarrow. Lexington, MA: Lexington Books, 55-58.
Grofman, Bernard. 1985. "Criteria for Districting: Science Perspective." UCLA Law Review 33: 77-184.

Grofman, Bernard. 1992. "Expert Witness Testimony and the Evolution of Voting Right Case Law." In Controversies in Minority Voting: The Voting Rights Act in Perspective, eds. Bernard Grofman, and Chandler Davidson. Washington, D.C.: The Brookings Institution, 197-229.

Grofman, Bernard. 2018a. "Crafting a Judicially Manageable Standard for Partisan Gerrymandering: Five Necessary Elements." Election Law Journal: Rules, Politics, and Policy 17(2): 117-136.

Grofman, Bernard. 2018b. "This Might Be the Way to Prove Partisan Gerrymandering, According to the New Supreme Court Standard." Washington Post. July 9.

Grofman, Bernard, and Gary King. 2007. "The Future of Partisan Symmetry as a Judicial Test for Partisan Gerrymandering after LULAC v. Perry." Election Law Journal 6(1): $2-35$.

Grofman, Bernard, and Jonathan R. Cervas. 2018. "Pennsylvania Has to Draw New Congressional Districts, but Getting Rid of Gerrymandering Will Be Harder Than You Think." Washington Post. February 9.

Grofman, Bernard, and Keith Gaddie. 2017. "Amicus Brief on Behalf of Neither Party in Gill v. Whitford." Supreme Court No. 16-1161 (U.S. 2017), filed August 19, 2017.

Grofman, Bernard, and Keith Gaddie. 2018. "Amicus Brief on Behalf of Neither Party in League of Women Voters v. Pennsylvania." On Appeal from the Order of the Commonwealth Court of Pennsylvania (No. 261 MD 2017), filed January 4, 2018.

Grofman, Bernard, and Thomas L Brunell. 2005. "The Art of the Dummymander: The Impact of Recent Redistrictings on the Partisan Makeup of Southern House Seats." In Redistricting in the New Millennium, ed. Peter F. Galderisi. Lanham, MD: Lexington Books, 183-199.

Grofman, Bernard, Christian Collet, and Robert Griffin. 1998. "Analyzing the Turnout-Competition Link with Aggregate Cross-Sectional Data." Public Choice 95(34): 233-246.

Kendall, M.G., and A. Stuart. 1950. "The Law of the Cubic Proportion in Election Results." British Journal of Sociology 1(3): 183-196.

Lai, Jonathan, and Liz Navratil. 2018. "SCOTUS Denies Pa. GOP Lawmakers' Attempt to Delay Drawing New Congressional Map, Philadelphia Inquirer (February 5).

League of Women Voters et al. v. Commonwealth of Pennsylvania et al. 2018. No. 159 MM 2017.

League of Women Voters v. Detzner. 2015. 172 So. 3d 363 (Fla.).

League of Women Voters of Michigan v. Johnson. No. 18-1437 (6th Cir. 2018).

McDonald, Michael D., and Robin E. Best. 2015. "Unfair Partisan Gerrymanders in Politics and Law: A Diagnostic Applied to Six Cases.” Election Law Journal 14(4): 312-330.

McGann, Anthony J., Charles Anthony Smith, Michael Latner, and Alex J. Keena. 2015. "A Discernable and Manageable Standard for Partisan Gerrymandering." Election Law Journal 14(4): 295-311.

McGann, Anthony J., Charles Anthony Smith, Michael Latner, and Alex Keena. 2016. Gerrymandering in America. Cambridge: Cambridge University Press. 
Miller, Peter, and Bernard Grofman. 2013. "Redistricting Commissions in the Western United States." UC Irvine Law Review 3: 637-668.

Niemi, Richard G., Bernard Grofman, Carl Carlucci, and Thomas Hofeller. 1990. "Measuring Compactness and the Role of a Compactness Standard in a Test for Partisan and Racial Gerrymandering." Journal of Politics 52(4): 1155-1181.

Owen, Guillermo, and Bernard Grofman. 1988. "Optimal Partisan Gerrymandering." Political Geography Quarterly 7(1): 5-22.

Page v. Va. State Bd. of Elections (Page II). 2015. Civil Action No. 3:13cv678 (E.D. Va. June 5, 2015).

Royden, Laura, and Michael Li. 2017. Extreme Maps. Technical report, Brennan Center for Justice. <https://www.brennan center.org/publication/extreme-maps $>$.

Shaw v. Hunt. 1996. 517 U.S. 899.

Theil, Henri. 1970. "The Cube Law Revisited." Journal of the American Statistical Association 65(331): 1213-1219.

Thornburg v. Gingles. 1986. 478 U.S. 30.
Wang, Samuel. 2016a. "Three Practical Tests for Gerrymandering: Application to Maryland and Wisconsin." Election Law Journal 15(4): 367-384.

Wang, Samuel. 2016b. "Three Tests for Practical Evaluation of Partisan Gerrymandering Stanford Law Review." Stanford Law Review 68: 1263-1321.

Wilson, Reid. 2018. "Ohio Voters Pass Redistricting Reform Initiative." The Hill. May 8.

Wuffle, A. 2015. "Uncle Wuffle's Reflections on Political Science Methodology.” PS: Political Science \& Politics 48(01): 176-182.

Address correspondence to: Jonathan R. Cervas

University of California, Irvine

3151 Social Science Plaza

Irvine, CA 92697-5100

E-mail: jcervas@uci.edu 